\title{
Seasonal Changes Impact on Growth of Rubber (Hevea brasiliensis) Seedlings under Different Cultivation
}

\author{
Dongling Qi1,2,3, Guishui Xie ${ }^{1,2,3}$, Zhixiang $\mathrm{Wu}^{1,2,3^{*}}$ \\ ${ }^{1}$ Rubber Research Institute, Chinese Academy of Tropical Agricultural Sciences, Haikou, China \\ ${ }^{2}$ Danzhou Investigation \& Experiment Station of Tropical Crops, Ministry of Agriculture and Rural Affairs, Danzhou, China \\ ${ }^{3}$ Key Laboratory of Biology and Genetic Resources of Rubber Tree, Ministry of Agriculture and Rural Affairs, Haikou, China \\ Email: *zhixiangwu@21cn.com
}

How to cite this paper: Qi, D. L., Xie, G. S., \& Wu, Z. X. (2019). Seasonal Changes Impact on Growth of Rubber (Hevea brasiliensis) Seedlings under Different Cultivation. Open Journal of Forestry, 9, 397-406. https://doi.org/10.4236/ojf.2019.94022

Received: September 22, 2019

Accepted: October 25, 2019

Published: October 28, 2019

Copyright $\odot 2019$ by author(s) and Scientific Research Publishing Inc. This work is licensed under the Creative Commons Attribution International License (CC BY 4.0).

http://creativecommons.org/licenses/by/4.0/

C) (i) Open Access

\begin{abstract}
The vegetative growth of rubber tree is an important basis for rubber tree cultivation and economic management. Stem diameter and height growth patterns of rubber seedlings and the seasonal variability are still poorly understood. Studying the annual growth patterns and seasonal variation of rubber seedling will help understanding biological characteristics of rubber tree and provide a reference for field cultivation and management. Height growth and stem diameter of field-sown rubber seedlings cultivation and polybag-raised cultivation all displayed a distinct annual pattern of "slow-fast-slow". Height growth and stem diameter growth response fitted the logistic equation preferably, supporting the observed pattern. Fast-growth of plant height for polybag-raised rubber seedlings cultivation and field-sown rubber seedlings cultivation occurred from June to November and May to November, respectively. This period saw the greatest accumulations of plant height growth for polybag-raised rubber seedlings cultivation and field-sown rubber seedlings cultivation accounting for $83.99 \%$ and $86.65 \%$ of total growth, respectively. Fast-growth of stem diameter for polybag-raised rubber seedlings cultivation and field-sown rubber seedlings cultivation occurred from June to November and May to November, respectively. This period saw the greatest accumulations of stem growth for polybag-raised rubber seedlings cultivation and field-sown rubber seedlings cultivation accounting for $86.71 \%$ and $84.60 \%$ of total growth, respectively. Polybag-raised rubber seedlings cultivation and field-sown rubber seedlings cultivation for the whole year had nine extension units and each month had one extension unit from May to November. Extension unit of for the whole year did not stop period and plant height growth rate has the seasonal difference. However, leaf phenophase of field-sown rubber
\end{abstract}


seedlings cultivation was earlier than that of polybag-raised rubber seedlings cultivation and each extension unit of field-sown rubber seedlings cultivation was greater than that of polybag-raised rubber seedlings cultivation. The precipitation had the greatest impact on seedlings growth under different cultivation. There was no period annually in which height growth and stem diameter growth did not occur and the fastest growth occurred during the rainy season. Plant height and stem diameter of rubber seedlings under different cultivation showed isogony phenomenon. Extension unit and leaf phenophase of polybag-raised rubber seedlings and field-sown rubber seedlings showed consistency and synchronization characteristic. Different cultivation of rubber seedling should take corresponding measures tending management and operation.

\section{Keywords}

Rubber (Hevea brasiliensis), Logistic Equation, Growth Patterns, Seasonal Change

\section{Introduction}

Industrial cultivation of rubber trees is carried out in more than 60 countries in Asia, Africa, South America, Central America and Oceania between the latitudes of $10^{\circ} \mathrm{N}$ and $15^{\circ} \mathrm{S}(\mathrm{Mo}, 2014)$. These areas farmers' income mainly comes from the rubber tree planting (Qi et al., 2016). It is an important part of height growth and diameter growth for plant vegetative growth and its growth is directly related to crop growth quality. The vegetative growth of rubber is main index to measure the rubber forest uniformity, no matter that rubber trees reach the standard for open tapping, but also an important basis for rubber Cultivation and economic management $(\mathrm{Wu}, 2007)$. Therefore, it is very meaningful to study on annual growth patterns of rubber. Construction of mathematical model is an effective way to quantitative research of plant growth dynamic process (Razali Wan et al., 2015; Zuhaidi, 2013). Vertical distribution of rubber groups' photosynthetic capacity varied under different crown density (Zhou et al., 1995). The predictions of rubber yield per unit area yearly by the joint Logistic-Markov forecasting model were actually matched and its predictive error was smaller than the predictive error of a single Logistic Model (Tang et al., 2009). Total biomass of forest stands increased with forest age by biomass estimation and biomass organ allocation of dry wood was the largest proportion (Obouayeba et al., 2000; Chandrasekhar, 2012). Annual diameter growth rates of rubber reduced after the first increase (Philippe \& Loïc, 1998; Tian et al., 2012), between ground organs and underground organs of rubber presented allometric phenomenon (Philippe \& Loïc, 1998; Tian et al., 2012). Rubber canopy photosynthesis simulation models were constructed based on the single leaf photosynthetic rate of the light distribution model (Xie et al., 2010). Stem diameter and height 
growth patterns of rubber seedlings and the seasonal variability are still poorly understood. Studying the annual growth patterns and seasonal variation of rubber seedling will help understanding biological characteristics of rubber tree and provide a reference for field cultivation and management. Here we analyze annual growth patterns of field-sown rubber seedlings by using of Logistic curve equation. The findings will provide reference for the Hevea brasiliensis seedling cultivation and production.

\section{Materials and Methods}

\subsection{Study Site}

The study area is located in the fifth experimental test area, Experiment Farm, Chinese Academy of Tropical Agricultural Sciences (CATAS), Danzhou city in the west of Hainan Province, China $\left(109^{\circ} 29^{\prime \prime} \mathrm{N}, 19^{\circ} 29^{\prime} \mathrm{E}\right)$. The area is classified as a subtropical monsoon climate zone with annual temperature between $23^{\circ} \mathrm{C}$ $25^{\circ} \mathrm{C}$ and annual rainfall of $1500-1900 \mathrm{~mm}$. Soil belongs to lateritic soil in tropical areas of southern China.

Field-sown rubber seedlings cultivation:

Rubber seeds were sown on September 19, 2013, and then transplanted from the seedbed to the field on October 15, 2013. According to $50 \mathrm{~cm} \times 25 \mathrm{~cm}$, these seedlings were managed according to conventional measures.

Polybag-raised rubber seedlings cultivation:

Rubber seeds were sown in seedbeds on September 19, 2013, and the seedlings were picked off, raised in polybags and arranged in the nursery on October 15, 2013 at a spacing of $(100 \mathrm{~cm}+11 \mathrm{~cm}) \times 11 \mathrm{~cm}$ in accordance with conventional management.

\subsection{Seedling Observation and Measurement}

Four plots were designed with 6 rows each plot. The seedlings in the central two 2 rows were marked with paint $5 \mathrm{~cm}$ from the raised bag soil, at which their height and stem diameter were measured with a vernier caliper. The measurement was done at the end of each month from December 2013 to December 2014. Extension unit and leaf phenophase activities were recorded at the time of each observation.

\subsection{Growth Curve Fitting under Different Cultivation}

Logistic equation was selected to fit growth process of rubber seedlings under different cultivation, which was expressed as follows:

$$
Y=c_{1} /\left(1+\exp \left(c_{2}+c_{3} t\right)\right)
$$

In the above formula, $c_{1}, c_{2}$ and $c_{3}$ are the growth parameters. $t$ is the amount of growth of the final value, and represents the blending coefficient is determined using the appropriate $\mathrm{R}^{2}$. Where $Y$ is accumulation of rubber seedling growth, and $t$ is the rubber seedlings growth days. 


\subsection{Analysis of Environmental Variables}

Net growth was set as the reference sequence $X_{0}$, and sunshine, precipitation and temperature were set as comparison sequence $X_{i}(i=1-3)$ to formulate a grey system to correlate the growth with meteorological factors.

These data were analyzed using Microsoft Excel and SPSS analysis software.

\section{Results}

\subsection{Seedling Growth}

Plant height growth of polybag-raised rubber seedlings and field-sown rubber seedlings had an S-shaped curve (Figure 1) showing a clear "slow-fast-slow" growth trend (Figure 2). Their growth course was partitioned into three periods, namely pro-slow-growth, fast-growth, late-slow-growth (Table 1). Fast-growth of plant height for polybag-raised rubber seedlings and field-sown rubber seedlings occurred from June to November and May to November, respectively. This period saw the greatest accumulations of plant height growth for polybag-raised rubber seedlings and field-sown rubber seedlings accounting for $83.99 \%$ and $86.65 \%$ of total growth, respectively (Table 1).

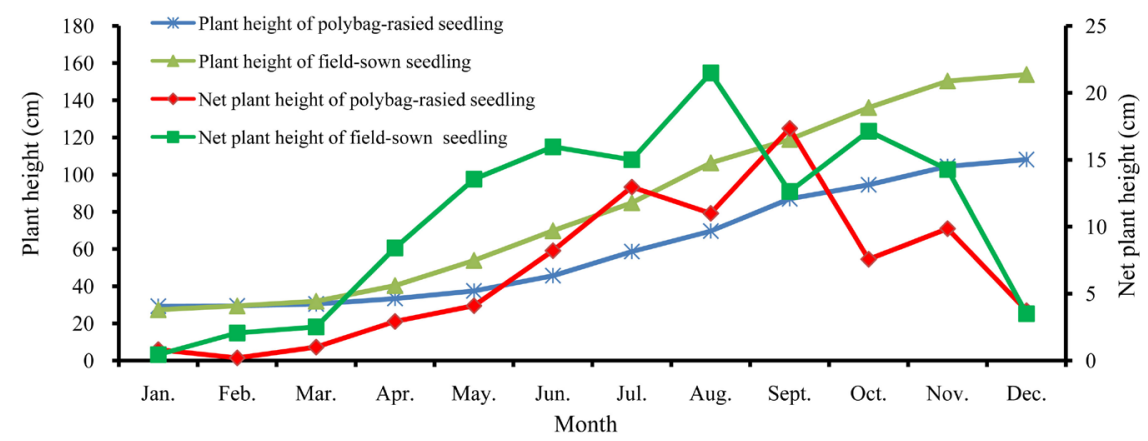

Figure 1. Growth process of plant height of rubber seedlings under different cultivation.

Table 1. The division of growth period and growth compare of rubber seedlings under different cultivation.

\begin{tabular}{|c|c|c|c|c|c|c|}
\hline Cultivation method & Item & Growth period & $\begin{array}{l}\text { Starting and } \\
\text { ending month }\end{array}$ & $\begin{array}{l}\text { Cumulative } \\
\text { time/d }\end{array}$ & $\begin{array}{c}\text { Net } \\
\text { growth/cm }\end{array}$ & $\begin{array}{l}\text { Proportion of the } \\
\text { total amount }\end{array}$ \\
\hline \multirow{6}{*}{$\begin{array}{l}\text { Polybag-raised } \\
\text { rubber seedlings }\end{array}$} & \multirow{3}{*}{ Plant height } & Early-slow-growth & January to May & 151 & 9.03 & $11.33 \%$ \\
\hline & & Fast-growth & June to November & 183 & 66.93 & $83.99 \%$ \\
\hline & & Late-slow-growth & December & 31 & 3.73 & $4.68 \%$ \\
\hline & \multirow{3}{*}{ Stem diameter } & Early-slow-growth & January to May & 151 & 0.46 & $5.82 \%$ \\
\hline & & Fast-growth & June to November & 183 & 6.85 & $86.71 \%$ \\
\hline & & Late-slow-growth & December & 31 & 0.59 & $7.47 \%$ \\
\hline \multirow{6}{*}{$\begin{array}{l}\text { Feld-sown } \\
\text { rubber seedlings }\end{array}$} & \multirow{3}{*}{ Plant height } & Early-slow-growth & January to April & 120 & 13.45 & $10.59 \%$ \\
\hline & & Fast-growth & May to November & 214 & 110.30 & $86.65 \%$ \\
\hline & & Late-slow-growth & December & 31 & 3.50 & $2.76 \%$ \\
\hline & \multirow{3}{*}{ Stem diameter } & Early-slow-growth & January to April & 120 & 1.29 & $9.15 \%$ \\
\hline & & Fast-growth & May to November & 214 & 11.92 & $84.60 \%$ \\
\hline & & Late-slow-growth & December & 31 & 0.88 & $6.25 \%$ \\
\hline
\end{tabular}




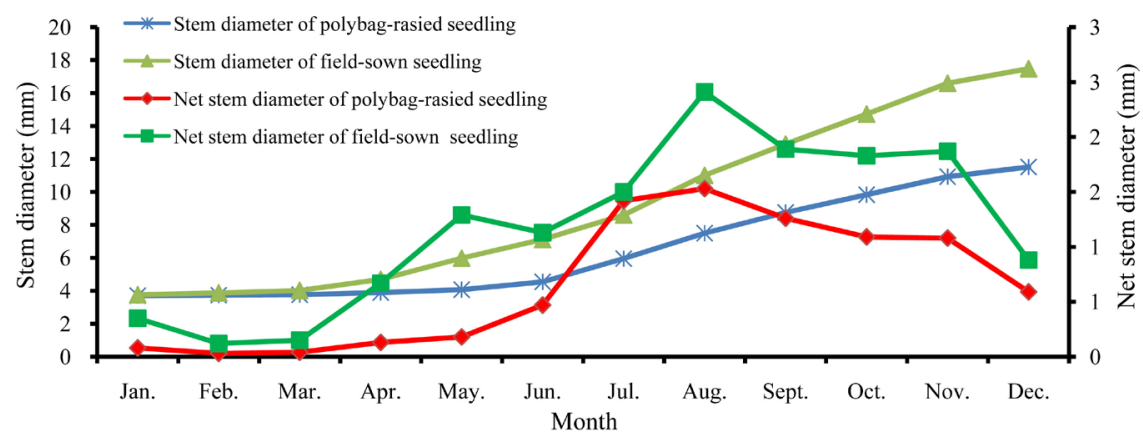

Figure 2. Growth process of stem diameter of rubber seedlings under different cultivation.

Stem growth of polybag-raised rubber seedlings and field-sown rubber seedlings had also an S-shaped curve showing a clear "slow-fast-slow" growth trend (Figure 2). Their growth course was partitioned into three periods, namely pro-slow-growth, fast-growth, late-slow-growth (Table 1). Fast-growth of stem diameter for polybag-raised rubber seedlings and field-sown rubber seedlings occurred from June to November and May to November, respectively. This period saw the greatest accumulations of stem growth for polybag-raised rubber seedlings and field-sown rubber seedlings accounting for $86.71 \%$ and $84.60 \%$ of total growth, respectively (Table 1 ).

\subsection{Isogony Phenomenon of Height and Stem Diameter Growth for Rubber Seedlings under Different Cultivation}

Height growth process curve and diameter growth process curve were depicted in the same coordinate system (Figure 3 and Figure 4). Growth stage of plant height and stem diameter for rubber seedlings under different cultivation was consistent. Pro-slow-growing, fast-growing and late-slow-growing stage of rubber seedling under polybag-raised rubber seedlings cultivation was 0 - 151 d, 152 - 334 d, 335 - 365 d, respectively. Pro-slow-growing, fast-growing and late-slow-growing stage of rubber seedling under field-sown rubber seedlings cultivation was 0 - $120 \mathrm{~d}, 121-334 \mathrm{~d}, 335-365 \mathrm{~d}$, respectively. Plant height and stem diameter of rubber seedlings under different cultivation showed isogony phenomenon.

\subsection{Extension Unit and Leaf Phenophase}

An extension unit is together constituted from the stems, leaves and buds, which parts form a continuous growth of the stem growing point of rubber seedling. Leaf phenology reflects phenomenon of canopy leaf morphology regular change for growth state of rubber seedling. In general, according to the headliner leaf blade morphology, leaf phenology is divided into elongating stage, leaf-expansion stage, light green stage and stationary stage. Extension unit and leaf phenophase of polybag-raised rubber seedlings and feld-sown rubber seedlings showed consistency and synchronization characteristic (Table 2). Two different cultivations 


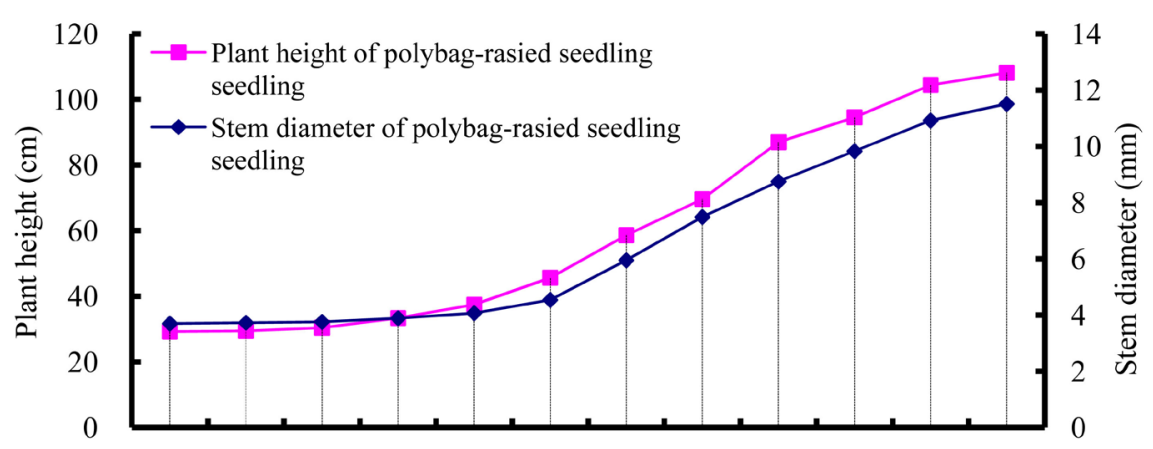

Jan. Feb. Mar. Apr. May. Jun. Jul. Aug. Sept. Oct. Nov. Dec.

Month

Figure 3. Comparison of growth process between plant heights and stem diameter of rubber container growing seedling.

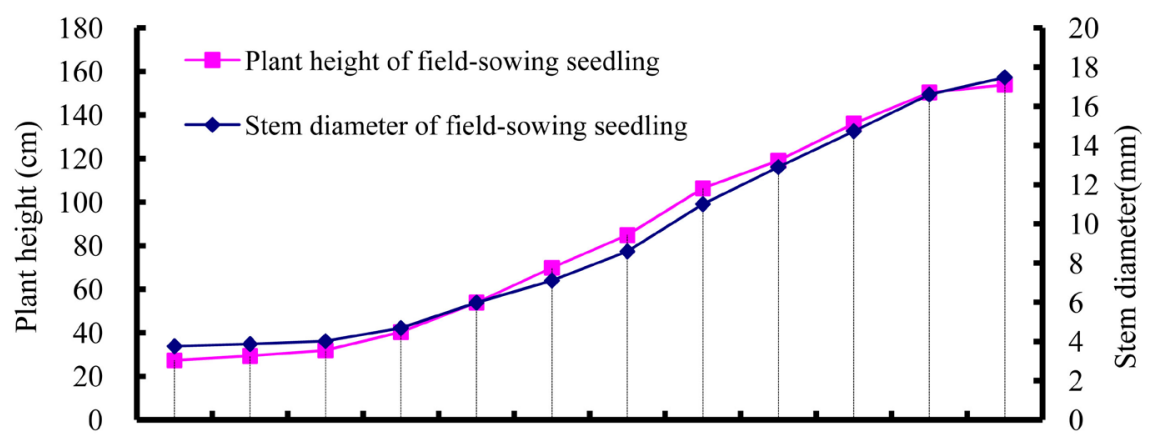

Jan. Feb. Mar. Apr. May. Jun. Jul. Aug. Sept. Oct. Nov. Dec.

\section{Month}

Figure 4. Comparison of growth process between plant heights and stem diameter of rubber ground growing seedling.

Table 2. Extension unit and leaf phenophase of growth period of rubber seedlings under different cultivation.

\begin{tabular}{ccccc}
\hline \multirow{2}{*}{$\begin{array}{c}\text { Growth } \\
\text { time }(\mathrm{M})\end{array}$} & \multicolumn{2}{c}{ Polybag-raised rubber seedlings } & \multicolumn{2}{c}{ Feld-sown rubber seedlings } \\
\cline { 2 - 5 } & Extension unit & Leaf phenophase & Extension unit & Leaf phenophase \\
\hline January & First & Elongating stage & First & Elongating stage \\
February & Second & Elongating stage & Second & Light green stage \\
March & Second & Light green stage & Second & Stationary stage \\
April & Second & Stationary stage & Second & Light green stage \\
May & Third & Stationary stage & Third & Light green stage \\
June & Fourth & Stationary stage & Fourth & Leaf-expansion \\
July & Fifth & Leaf-expansion stage & Fifth & Leaf-expansion stage \\
August & Sixth & Elongating stage & Sixth & Leaf-expansion \\
September & Seventh & Leaf-expansion & Seventh & Leaf-expansion \\
October & Eighth & Stationary stage & Eighth & Stationary stage \\
November & Ninth & Stationary stage & Ninth & Stationary stage \\
December & Ninth & Stationary stage & Ninth & Stationary stage \\
\hline
\end{tabular}


between polybag-raised rubber seedlings and field-sown rubber seedlings for the whole year had nine extension units and each month had one extension unit from May to November. Extension unit of for the whole year did not stop period and plant height growth rate has the seasonal difference. Howeverr, leaf phenophase of feld-sown rubber seedlings cultivation was earlier than that of polybag-raised rubber seedlings cultivation, and each extension unit of feld-sown rubber seedlings cultivation was greater than that of polybag-raised rubber seedlings cultivation.

\subsection{Fitting and Stem Diameter Seedlings Growth Curve}

High growth and stem diameter growth models were developed using high and stem diameter observational data and Logistic equation were formulated to describe the height growth and diameter growth dynamics. The results showed the actual observations of high and stem diameter for polybag-raised rubber seedlings cultivation made by the growth curve fitting curve consistent with the predicted values was high, the coefficient of determination, respectively, $95.68 \%$ and 95.12\%, and the choice of Logistic curve was fitted rubber seedlings height and stem diameter growth. Meanwile, the actual observations of high and stem diameter for field-sown rubber seedlings cultivation made by the growth curve fitting curve consistent with the predicted values was high, the coefficient of determination, respectively, $98.76 \%$ and $97.50 \%$, and the choice of Logistic curve was fitted rubber seedlings height and stem diameter growth (Table 3).

Table 3. Growth model for plant height and stem diameter of rubber seedlings.

\begin{tabular}{|c|c|c|c|c|c|c|c|}
\hline Item & Regression equation & Sources of variance & Quadratic sum & $\mathrm{df}$ & Mean square & F value & $P$ value \\
\hline $\begin{array}{l}\text { Polybag-raised } \\
\text { rubber seedlings } \\
\text { cultivation }\end{array}$ & & Return variance & 10435.7478 & 2 & 5188.7783 & 106.6694 & 0 \\
\hline \multirow[t]{4}{*}{ Plant height } & $Y=151.1238 /(1+\exp (2.1144-0.008441 t))$ & Remaining variance & 449.1744 & 9 & 49.9083 & & \\
\hline & & Total variance & 10884.9222 & 11 & 948.2182 & & \\
\hline & & $\mathrm{R}=0.9782$ & $\mathrm{R}^{2}=0.9568$ & & & & \\
\hline & & Return variance & 97.9806 & 2 & 49.1819 & 93.7926 & 0 \\
\hline \multirow[t]{3}{*}{ Stem diameter } & $\mathrm{Y}=42.8505 /(1+\exp (2.8662-0.162773 \mathrm{t}))$ & Remaining variance & 5.153 & 9 & 0.554 & & \\
\hline & & Total variance & 103.1336 & 11 & 9.4008 & & \\
\hline & & $\mathrm{R}=0.9753$ & $\mathrm{R}^{2}=0.9512$ & & & & \\
\hline Field-sown & & & & & & & \\
\hline $\begin{array}{l}\text { rubber seedlings } \\
\text { cultivation }\end{array}$ & & Return variance & 27032.0321 & 2 & $14,103.1011$ & 368.4851 & 0 \\
\hline \multirow[t]{4}{*}{ Plant height } & $Y=182.6208 /(1+\exp (2.5609-0.011803 t))$ & Remaining variance & 332.1691 & 9 & 36.9077 & & \\
\hline & & Total variance & 27364.2012 & 11 & 2435.3507 & & \\
\hline & & $\mathrm{R}=0.9938$ & $\mathrm{R}^{2}=0.9876$ & & & & \\
\hline & & Return variance & 343.4606 & 2 & 164.2229 & & \\
\hline \multirow[t]{3}{*}{ Stem diameter } & $\mathrm{Y}=30.5550 /(1+\exp (2.5715-0.007963 t))$ & Remaining variance & 8.2687 & 9 & 0.9116 & & \\
\hline & & Total variance & 351.7293 & 11 & 29.4591 & & \\
\hline & & $\mathrm{R}=0.9874$ & $\mathrm{R}^{2}=0.9750$ & & & & \\
\hline
\end{tabular}




\subsection{Correlation Analysis between Seedlings Growth and the Major Environmental Factors}

Coarse gray correlation analysis between seedling growth of polybag-raised rubber seedlings cultivation and feld-sown rubber seedlings cultivation and main environmental factors indicated the meteorological factors had different impacts, of which the precipitation had the greatest impact on seedlings growth (Table 4).

\section{Discussion}

Annual diameter growth of mature rubber tree is generally stabile (Guilherme et al., 2014). Stem diameter growth of a Hevea brasiliensis clone CATAS7-33-97 from first seven years of growth showed regular linear growth (Zhou et al., 2013). Cumulative stem diameter growth is for six years after Ivorian planting reached standards of tappability (Obouayeba et al., 2000). The characteristics of inter annual change around India's major cultivar RRII 105 growth rate after planting for second to twelfth years firstly increased and then decreased (Chandrasekhar, 2012). Ariff E et al. (2011) studies have also shown that the diameter of rubber tree was a significant difference in immature growth stage. In this study, the annual growth patterns of polybag-raised rubber seedlings cultivation and feld-sown rubber seedlings cultivation are partitioned into three periods of time, namely early-slow-growth, fast-growth, and late-slow-growth stage. Kathy et al. (Kathy et al., 2015) thought it was still lacking an integrative framework to assess impacts of climate on stem growth in trees studied in anatomical, ecophysiological, and ecological disciplines, but an integrative framework to those impacts remains lacking.

In this study, the greatest impact environmental infector on the height growth and stem diameter growth under different cultivation all is precipitation, and which could result in the isogony phenomenon of plant height and stem diameter. The result showed one growth index selected from among height growth and stem diameter can be monitored the seedlings growth dynamic. Otherwise, two different cultivations between polybag-raised rubber seedlings and field-sown rubber seedlings each month had one extension unit from May to November.

Table 4. Analysis of correlation between seedlings growth and major environmental 1 Factors.

\begin{tabular}{cccc}
\hline Correlation degree & $\begin{array}{c}\text { Aerial } \\
\text { temperature } /{ }^{\circ} \mathrm{C}\end{array}$ & Precipitation/mm & $\begin{array}{c}\text { Solar radiation } \\
\text { hours } / \mathrm{h}\end{array}$ \\
\hline Polybag-raised rubber seedlings cultivation & & & \\
Plant height & 0.2845 & 0.4003 & 0.3491 \\
Stem diameter & 0.2248 & 0.3915 & 0.2164 \\
Field-sown rubber seedlings cultivation & & & \\
Plant height & 0.3622 & 0.4764 & 0.3937 \\
Stem diameter & 0.3726 & 0.5223 & 0.3657 \\
\hline
\end{tabular}


Fast-growth of field-sown rubber seedlings cultivation is earlier than one month that of polybag-raised rubber seedlings cultivation. Combined with seedling growth rhythm, different cultivation has different strategies of cultivation and management techniques can be developed, then which can realize the fast-growing rubber seedlings.

The Logistic equation successfully fitted the stand volume and hectare of rubber plantations in Malaysia (Suratman et al., 2004). Logistic equation was fitted to the growth of rubber tree in order to assess intercropping effect in immature period (Rodrigo et al., 2005). Logistic equation fitted the height growth and stem diameter growth of the polybag-raised rubber seedlings in this study.

This study is geographically and temporally limited. Whether results are applicable to other regions in China and whether there is substantial interannual variation in growth still needs to be studied.

\section{Conclusion}

There was no period annually in which height growth and stem diameter growth did not occur and the fastest growth occurred during the rainy season. Plant height and stem diameter of rubber seedlings under different cultivation showed isogony phenomenon. Extension unit and leaf phenophase of polybag-raised rubber seedlings and field-sown rubber seedlings showed consistency and synchronization characteristic. Different cultivation of rubber seedling should take corresponding measures tending management and operation.

\section{Acknowledgements}

This research was funded by the earmarked fund for China Agriculture Research System (CARS-34-ZP3).

\section{Conflicts of Interest}

The authors declare no conflicts of interest regarding the publication of this paper.

\section{References}

Ariff, E. A. R. E., Suratman, M. N., \& Abdullah, S. (2011). Stomatal Conductance, Chlorophyll Content, Diameter and Height in Different Growth Stages of Rubber Tree (Rubber) Saplings (pp. 84-88). Langkawi, Malaysia: 2011 IEEE Symposium Business, Engineering and Industrial Applications (ISBEIA).

Chandrasekhar, T. R. (2012). Evaluation of Unconstrained and Constrained Mathematical Functions to Model Girth Growth of Rubber Trees (Hevea brasiliensis) Using Young Age Measurements. Journal of Forestry Research, 23, 365-375. https://doi.org/10.1007/s11676-012-0272-2

Guilherme, A. P. S., Lígia, R. L. G., Cecília, K. V., André, L. B. O., \& Paulo, S. G. (2014). Annual Growth Increment and Stability of Rubber Yield in the Tapping Phase in Rubber Tree Clones: Implications for Early Selection. Industrial Crops and Products, 52, 801-808. https://doi.org/10.1016/j.indcrop.2013.12.010

Kathy, S., Frank, S., \& Annie, D. (2015). Diel Growth Dynamics in Tree Stems: Linking 
Anatomy and Ecophysiology. Trends in Plant Science, 20, 335-343. https://doi.org/10.1016/j.tplants.2015.03.015

Mo, Y. Y. (2014). There Is More Than 60 Countries Worldwide Scale Cultivation of Rubber Tree. China Tropical Agriculture, 5, 75-76.

Obouayeba, S., Boa, D., Gohet, E., Dian, K., Ouattara, N., \& Keli, Z. J. (2000). Dynamics of Vegetative Growth of Rubber in Determining Tapping Norms. Journal of Rubber Research, 3, 53-62.

Philippe, T., \& Loïc, P. (1998). Modeling the Influence of Assimilate Availability on Root Growth and Architecture. Plant and Soil, 201, 307-320.

https://doi.org/10.1023/A:1004380021699

Qi, D. L., Zhou, J. N., Xie, G. S., \& Wu, Z. X. (2016). Optimizing Tapping-Tree Density of Rubber (Hevea brasiliensis) Plantations in South China. Small-Scale Forestry, 15, 61-72. https://doi.org/10.1007/s11842-015-9308-8

Razali Wan, W. M., Razak Abdul, T., Azani Mohamad, A., \& Kamziah, A. K. (2015). Mixed-Effects Models for Predicting Early Height Growth of Forest Trees Planted in SARAWAK, MALAYSIA. Journal of Tropical Forest Science, 27, 267-276.

Rodrigo, V. H. L., Stirling, C. M., Silva, T. U. K., \& Pathirana, P. D. (2005). The Growth and Yield of Rubber at Maturity Is Improved by Intercropping with Banana during the Early Stage of Rubber Cultivation. Field Crops Research, 91, 23-33.

https://doi.org/10.1016/j.fcr.2004.05.005

Suratman, M. N., Bull, G. Q., Leckie, D. G., Lemay, V. M., Marshall, P. L., \& Mispan, M. R. (2004). Prediction Models for Estimating the Area, Volume, and Age of Rubber (Hevea brasiliensis) Plantations in Malaysia Using Landsat Landsat TM Data. International Forestry Review, 6, 12. https://doi.org/10.1505/ifor.6.1.1.32055

Tang, J. W., Pang, J. P., Chen, M. Y., Guo, X. M., \& Zeng, R. (2009). Biomass and Its Estimation Model of Rubber Plantations in Xishuangbanna, Southwest China. Chinese Journal of Ecology, 28, 1942-1948.

Tian, Y. H., Yue, H., Long, Y. F., \& Chen, G. Y. (2012). Application of the FracRoot Model in the Root Study of Rubber Tree Species. Chinese Journal of Tropical Crops, 33, 33-36.

Wu, J. L. (2007). Study on Stem Diameter Growth of Rubber Tree. Journal of Hainan State Farm Science and Technology, 2, 7-15.

Xie, G. S., Chen, B. Q., Wang, J. K., Wu, Z. X., \& Huang, W. F. (2010). Studies on the Simulation Model of Photosynthesis and Dry Matter Accumulation for Rubber Tree. Chinese Agricultural Science Bulletin, 26, 317-323.

Zhou, L. J., Wang, J., Chen, X. H., \& Lin, W. F. (2013). A comparative Study on the Different Building of Rubber in the Immature Period. Chinese Agricultural Science Bulletin, 29, 26-29.

Zhou, Z. Z., Zheng, H. S., Yin, G. T., Yang, Z. J., \& Chen, K. T. (1995). Biomass Equations for Rubber Tree in Southern China. Forest Research, 8, 624-629.

Zuhaidi, A. Y. (2013). Crown Diameter Prediction Model for Plantation Grown Neolamarckia Cadamba. Journal of Tropical Forest Science, 25, 446-453. 